\title{
Comparison Between Pendant Position and Traditional Sitting Position for Successful Spinal Puncture in Spinal Anesthesia for Cesarean Section
}

\author{
Pryambodho Pryambodho, ${ }^{1, *}$ Alfan Mahdi Nugroho, ${ }^{1}$ and Desy Januarrifianto ${ }^{1}$ \\ ${ }^{1}$ Department of Anesthesiology and Intensive Care, Faculty of Medicine, Universitas Indonesia, Jakarta, Indonesia \\ "Corresponding author: Pryambodho Pryambodho, Department of Anesthesiology and Intensive Care, Faculty of Medicine, Universitas Indonesia, Cipto Mangunkusumo \\ Hospital, Jl. Salemba Raya 6, Jakarta 10430, Indonesia. Tel: +62-213143736, E-mail: pryambodho.pry@icloud.com
}

Received 2017 January 12; Revised 2017 February 13; Accepted 2017 March 15.

\begin{abstract}
Background: Success of spinal anesthesia in pregnant females is strongly influenced by the position of the patient at the time of spinal insertion. Pendant position is a new position introduced to increase the intervertebral spaces. The current study aimed at comparing successful spinal puncture among the patients with pendant position in comparison with the ones with traditional sitting position for the elective caesarean section.

Methods: The current study was a non-blinded, randomized controlled trial (RCT) (registration code: NCT02753660 (ClinicalTrial.gov) on pregnant females undergoing spinal anesthesia. The participants were divided into 2 groups by the random consecutive sampling method; group A (pendant position) and group B (traditional sitting position). The successful placement of spinal needle was determined by the number of attempts, the amount of bone contact, and the time of spinal puncture. The inclusion criteria were pregnant females aged 18 to 45 years, body mass index (BMI) of 18 to $35 \mathrm{~kg} / \mathrm{m}^{2}$, and the physical status I to III, based on American society of anesthesiologists classification (ASA).

Results: Following the approval of the ethical committee, 308 subjects were enrolled in the study. The rate of successful puncture on the 1st attempt of group A was significantly high $(92 \%$ vs. $78 \%$, P value $=0.001)$. Additionally, group A had significantly less total amount of bone contact (185 vs. 421, P value < 0.001) and shorter time for spinal puncture ( 9 seconds vs. 12 seconds, P value $<0.001$ ). Conclusions: Pendant position was significantly better than traditional sitting position to provide successful 1st attempt spinal puncture in pregnant females undergoing cesarean section.
\end{abstract}

Keywords: Duration of Spinal, Pendant Position, Spinal-Bone Contact, Spinal Needle Puncture

\section{Background}

In pregnant females, it is difficult to perform lumbar flexion due to lumbar hyperlordosis that usually occur during pregnancy. Hyperlordosis can change the relationship between surface anatomy of vertebrae and vertebral columns. During pregnancy, due to these changes, the intervertebral spaces are narrow and can make the median approach for spinal puncture more difficult (1-3).

Filho et al. mentioned that the success rate of spinal needle placement in subarachnoid space was influenced by the anatomy of vertebrae, appropriate patient position, and the experience of the anesthesiologist. Incorrect position led to multiple insertion attempts which led to patients' inconvenience and increased complications (4). Multiple insertion attempts were also associated with postspinal back pain $(2,3,5)$. Precise identification of intervertebral space and interlaminar foramen may decrease contact between spinal needle and bone. This identification may be facilitated by decreasing lumbar lordosis during the spinal anaesthesia $(2,3,6,7)$.
Shabanian et al. reported that axillary support during sitting position might increase the intervertebral spaces. This position is called pendant position. Pendant position decreases the vertical pressure due to gravitation. Hence, this position increases the intervertebral spaces and the spinal needle may reach the subarachnoid space more accurately (8).

Pendant position is a newly introduced position for spinal anesthesia. Currently, no many studies addressed this position. Therefore, the current study aimed at comparing the pendant position with traditional sitting position regarding the success rate of 1st attempt spinal puncture, the number of spinal needle-bone contact, and duration of spinal puncture between the 2 positions among patients undergoing cesarean section.

\section{Methods}

It was a non-blinded, randomized controlled trial (RCT) conducted on the patients who were the candidate

Copyright ( $)$ 2017, Anesthesiology and Pain Medicine. This is an open-access article distributed under the terms of the Creative Commons Attribution-NonCommercial 4.0 International License (http://creativecommons.org/licenses/by-nc/4.0/) which permits copy and redistribute the material just in noncommercial usages, provided the original work is properly cited. 
for cesarean section in Budi Kemuliaan hospital, Jakarta, Indonesia, from August to October 2014. The spinal anesthesia was performed by 1 senior anesthesiology resident with more than 100 cases of spinal anesthesia experience. The protocol of the current study was approved by the ethical committee of faculty of medicine Universitas Indonesia (code number: 454/H2.F1/ETIK/2014) prior to conducting the study (Figure 1).

The current study utilized the random consecutive sampling method. Patients with pendant position were included in group A, while the ones with traditional sitting position were in group B. The inclusion criteria were the pregnant females aged 18 to 45 years, body mass index (BMI) 18 to $35 \mathrm{~kg} / \mathrm{m}^{2}$, physical status I to III, based on American society of anesthesiologists classification (ASA). The eligible cases who were the candidate for cesarean section with spinal anesthesia were enrolled in the study after signing the informed consent form. The exclusion criteria were any contraindications for spinal anesthesia (infection on injection site, coagulation disorder, severe hypovolemia, increased intracranial pressure, aortic and/or mitral stenosis), fetal head entrapment, umbilical cord prolapse, feet presentation, eclampsia, cardiovascular disease, scoliosis, history of lumbar surgery, and impalpable intervertebral space due to thick fatty tissue or edema. The subjects were dropped out from the study if the spinal block failed or in case of partial block, then the spinal anesthesia was converted into general anesthesia.

After skin injection of local anesthetic $1 \mathrm{~mL}$ lidocaine $2 \%$ at L4-L5, spinal anesthesia was performed using spinal needle Quincke 27G without introducer. The needle was directed horizontally with median approach. In case of bone contact, needle was retrieved until subcutaneous tissue and put on cephalic direction $\left(10^{\circ}\right)$. The maximum bone contact was 5 times. In case of more than 5 bone contacts, the spinal needle was inserted in L3-L4. In the case of more than 5 times bone contacts, subjects were dropped out and the general anesthesia was administered.

For each case the following parameters were recorded: the number of attempts for the successful spinal puncture, the number of spinal needle-bone contacts, and the time to perform spinal puncture.

Data were analyzed by statistical package for the social sciences (SPSS) version 21.0. Numerical data were scientific in mean, with minimal and maximal values. Numerical data were analyzed by the Mann-Whitney test. Categorical data were served by relative risk (RR) with $95 \%$ confidence interval (95\% CI) and analyzed by the Chi-square test.

\section{Results}

The current study recruited 308 subjects and divided them into Group A $(\mathrm{n}=154)$ and Group B $(\mathrm{n}=154)$ (Table 1$)$.

Table 1. Demographic Data of the Study Subjects

\begin{tabular}{lcc}
\hline & Group A $(\mathbf{n}=\mathbf{1 5 4})$ & Group B (n=154) \\
\hline Age, $\mathbf{y}$ & $31(18-42)$ & $30(18-43)$ \\
Body weight, kg & $58(38-80)$ & $57(38-85)$ \\
\hline Body height, cm & $155(137-167)$ & $155(140-170)$ \\
\hline BMI, kg/m ${ }^{2}$ & $24(18-33)$ & $24(18-33)$ \\
\hline ASA physical status & & $143(51.1)$ \\
\hline \multicolumn{1}{c}{ II } & $137(48.9)$ & $11(39.3)$ \\
\hline \multicolumn{1}{c}{ III } & $17(60.7)$ & \\
\hline
\end{tabular}

The mean number of spinal puncture attempts in group A was 1, ranged from 1 to 3; however, the mean value was also 1 in group B, ranged from 1 to 4 . Success rate of spinal puncture at 1st attempt was higher in group A than group B ( $92 \%$ vs. $78 \%$ ). Table 2 shows that group B required longer time for the spinal puncture in comparison with group A (12 seconds vs. 9 seconds). There was a significant difference between the groups regarding the number of attempts and the time for successful spinal puncture (Pvalue $<0.001$ ) (Table 3).

Table 2. Spinal Needle Placement Attempts for Groups A and B ${ }^{\mathrm{a}}$

\begin{tabular}{|c|c|c|c|}
\hline & Group A & Group B & PValue \\
\hline Number of puncture attempts & $1(1-3)$ & $1(1-4)$ & $0.001^{\mathrm{b}}$ \\
\hline Spinal needle-bone contacts & $0(0-13)$ & $1(0-15)$ & $<0.001^{\mathrm{b}}$ \\
\hline $\begin{array}{l}\text { Duration of spinal needle } \\
\text { insertion (seconds) }\end{array}$ & $9(4-350)$ & $12(5-486)$ & $<0.001^{b}$ \\
\hline
\end{tabular}

The number of spinal needle-bone contacts was higher in group A than group B (54\% vs. $35 \%$ ). Table 4 shows that group A had 1.56 higher risk of no spinal needle-bone contact in comparison with Group B (P value < 0.005).

\section{Discussion}

It was a pilot study on pendant position to measure the success rate of spinal puncture in Indonesian pregnant females. Indonesian population has middle-average body height, and this condition leads to narrower intervertebral spaces in comparison with the Caucasian population. Narrow intervertebral spaces and pregnancy might increase 


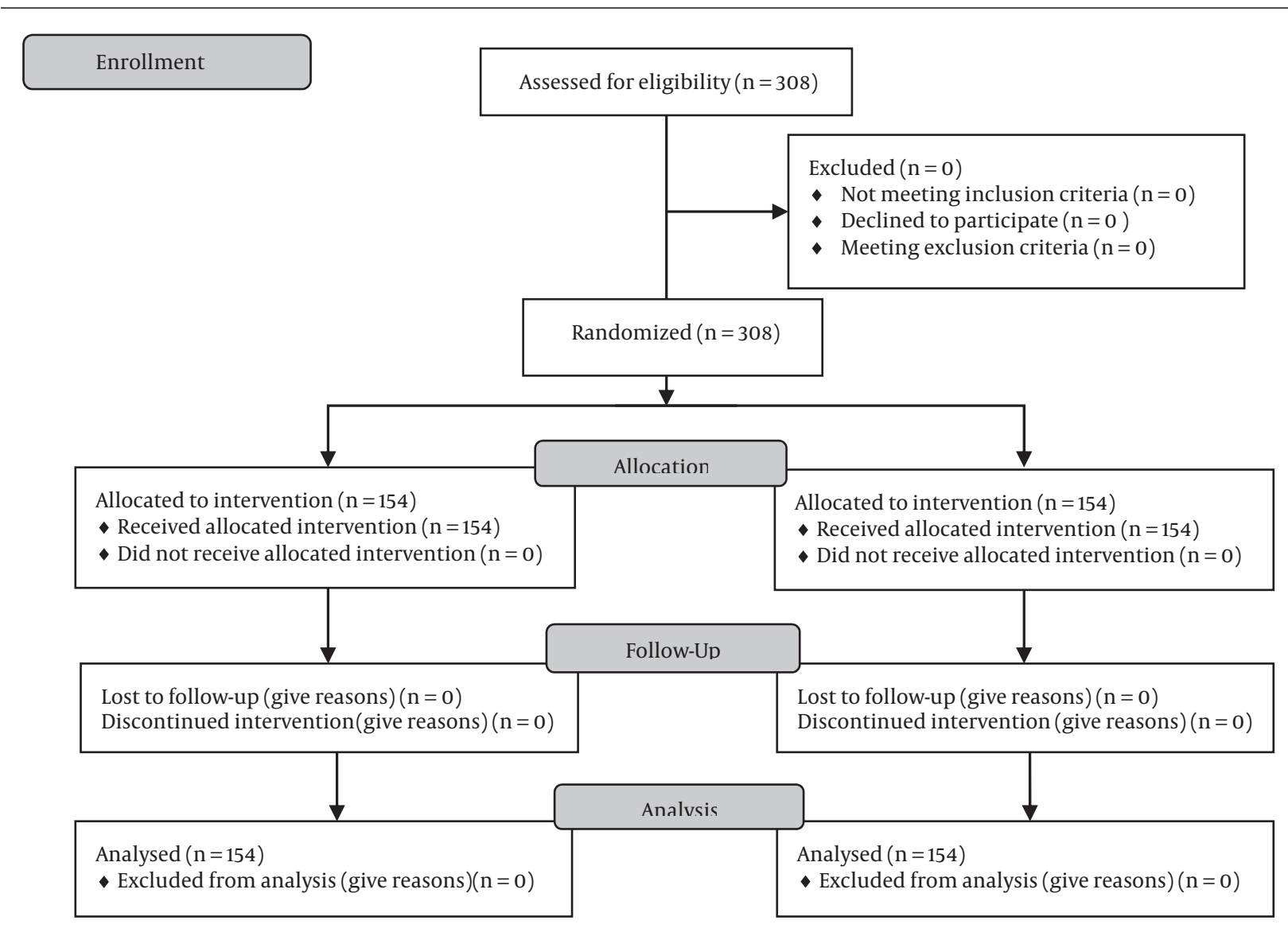

Figure 1. Flow Chart of the Study

Table 3. The Relationship Between the Positions and Success Rate of Puncture Attempts

\begin{tabular}{lcccc}
\hline & First Attempt, \% & Non-First Attempt, \% & PValue & RR \\
\hline Group A & $142(92)$ & $12(8)$ & $0.0007^{\mathrm{a}}$ & 1.17 \\
Group B & $121(78)$ & $33(22)$ & \\
\hline
\end{tabular}

${ }^{\mathrm{a}}$ Chi-Square test; power $91 \%$.

Table 4. The Relationship Between Positions and Spinal Needle-Bone Contacts

\begin{tabular}{|c|c|c|c|c|c|}
\hline & No Contacts, $\%$ & Spinal Needle-Bone Contacts, $\%$ & PValue & $\mathbf{R R}$ & 95\%CI \\
\hline Group A & $84(54)$ & $70(46)$ & $0.0005^{\mathrm{a}}$ & 1.56 & $1.2-2.02$ \\
\hline Group B & $54(35)$ & $100(65)$ & & & \\
\hline
\end{tabular}

${ }^{\mathrm{a}}$ Chi-Square test; power 90\%

the difficulty during spinal anesthesia, especially in median approach spinal needle insertion. Grau et al. mentioned that the mean of intervertebral spaces for pregnant females was $10.7 \mathrm{~mm}$, while in non-pregnant females it was
11.6 mm (P value < 0.006) (9). However, no study mentioned the size of intervertebral spaces among Indonesian population $(10,11)$.

The current study found that the success rate of spinal 
puncture in the 1st attempt in pendant position was significantly higher (P value $<0.05$ ) in comparison with that of traditional sitting position (92\% vs. 78\%). Patients with pendant position had 1.17 times higher chance to achieve 1st attempt success during spinal puncture in comparison with the ones with traditional sitting position (P value $<0.05$ ).

Patients with pendant position had significantly lower spinal needle-bone contacts in comparison with the ones with traditional sitting position ( $\mathrm{P}$ value $<0.05$ ). There were $54 \%$ and $35 \%$ successful punctures without bone contact in Groups A and B, respectively. Patients with pendant position had 1.56 times higher chance not to encounter bone contact in comparison with the subjects with traditional sitting position.

Spinal needle-bone contact was defined as the number of contacts between the spinal needle and hard surface (bone) during the spinal puncture, which might influence the spinal needle movement $(6,7)$. The current study limited the spinal needle-bone contacts to 5 times on 1 intervertebral space. The spinal needle insertion was changed to intervertebral space L3-L4; in case of more than 5 spinal needle-bone contacts in intervertebral L4-L5. In case of bone contact more than 5 times in intervertebral space L3-L4, the spinal needle insertion was changed to intervertebral L5-S1. One attempt was defined as a puncture performed from the skin surface. Withdrawing subcutaneously and redirecting the needle after unsuccessful attempts without drawing out of skin was still considered as one spinal puncture attempt. There was no maximum limitation for the number of spinal needle-bone contacts and attempts. Fewer number of spinal needle-bone contacts in the pendant position group might be influenced by widening of intervertebral spaces due to gravitation effect.

Spinal needle-bone contact during spinal anesthesia might increase the inconvenience of the patient and increase postspinal back pain incidence. The complications following frequent spinal needle-bone contact were associated with periosteal trauma (12). Unfortunately, the study did not conduct long-term follow-up to measure the pain postspinal anesthesia.

The current study showed that pendant position in pregnant patients had significantly higher success rate in the 1st attempt spinal puncture, less spinal needle-bone contact, and shorter time of spinal needle insertion puncture compared to the traditional sitting position, however, further studies are still needed to recommend the pendant position as an option in failed spinal anesthesia under traditional sitting position. Failed spinal anesthesia cases were not only caused by patient's position. Other factors such as patient's anatomical structure, anesthetist's experiences, and utilization of introducer were also influential.

The current study did not utilize the introducer during the spinal puncture needle placement. Introducer might decrease the number of spinal needle contact with the bone. Brooks et al. mentioned that patients who underwent spinal anesthesia without introducer had multiple insertion attempts in comparison to the ones with introducer (13).

The current study found that the time required for spinal puncture in pendant position was significantly shorter than that of the traditional sitting position ( $9 \mathrm{sec}-$ onds vs. 12 seconds, $P$ value $<0.05$ ). No literature mentioned the ideal time to conduct spinal needle insertion. However, both 9 and 12 seconds were considerably acceptable. The duration of spinal puncture was measured from the injection of spinal needle through the skin until reaching to the subarachnoid space, confirmed by the presence of free flow cerebrospinal fluid (CSF) in the spinal needle connector. In the current study, the preparation time needed for the patient was not measured. However, patients with pendant position might require longer preparation time, because they required adjustment for the support for optimal position.

Some studies mentioned that a successful spinal anesthesia could be assessed by the motoric block scoring. However, the current study defined that spinal anesthesia was successful if the presence of spinal needle in subarachnoid space confirmed by clear and free outflow of CSF from spinal needle, and good CSF aspiration with no blood (7). If blood was present in the spinal needle connector, the spinal needle should be withdrawn for $1 \mathrm{~mm}$. This maneuver was done repeatedly if necessary, until there was no blood, and free flow CSF and good CSF aspiration were observed. The current study did not measure the success of spinal anesthesia with the local anesthetic agent factor, the block level, and the side effect of local anesthetic agents. All spinal anesthesia inductions in the 2 groups were successfully worked as single modality anesthesia for caesarean section. There was no partial block or conversion to general anesthesia in the 2 groups.

The limitation of the current study was the lumbar intervertebral space determined only by palpating the point between the right and left iliac crests (the Tuffier line). However, the point was not confirmed with ultrasound. Pregnant females might also have changes of anatomical landmark, such as shifting of the Tuffier line to the cephalic direction. Therefore, the location of spinal needle insertion might differ from the true intervertebral level. The effect of pendant position on intervertebral spaces was not proven by radiologic study. Therefore, there was no sufficient basic data. 


\subsection{Conclusions}

The current study concluded that in pregnant females, pendant position had significantly higher success rate for the 1st attempt spinal puncture, less spinal needle-bone contact, and shorter duration of spinal needle insertion puncture compared to those of the traditional sitting position.

\section{Acknowledgments}

Authors would like to express their gratitude to the Department of Anesthesiology and Intensive Care, Faculty of Medicine, Universitas Indonesia.

\section{Footnotes}

Authors' Contribution: Study concept and design: Pryambodho, Alfan Mahdi Nugroho, and Desy Januarrifianto; analysis and interpretation of data: Pryambodho, Alfan Mahdi Nugroho, and Desy Januarrifianto; drafting of the manuscript: Pryambodho, Alfan Mahdi Nugroho, and Desy Januarrifianto; critical reversion of the manuscript for important intellectual content: Pryambodho, Alfan Mahdi Nugroho, and Desy Januarrifianto; statistical analysis: Pryambodho, Alfan Mahdi Nugroho, and Desy Januarrifianto.

Financial Disclosure: Authors declared no financial disclosure to the current study.

Funding/Support: The current study was supported by Department of anesthesiology and intensive care, faculty of medicine, Universitas Indonesia.

\section{References}

1. Chestnut DH, Wong CA, Tsen LC, Kee WDN, Beilin Y, Mhyre J. Chestnut's obstetric anesthesia: principles and practice. Elsevier Health Sciences; 2014
2. Wong CA, Nathan N, Brown DL. In: Chestnut obstetric anesthesia: Principles and practice. Chestnut DH, editor. Philadelphia: Elsevier Mosby; 2013. pp. 223-45.Spinal, epidural, and caudal anesthesia: Anatomy, physiology, and technique.

3. Tsen LC. In: Chestnut obstetric anesthesia: Principles and practice. Chestnut DH, editor. Philadelphia: Elsevier Mostby; 2013. pp. 52173.Anesthesia for cesarean delivery.

4. de Oliveira Filho GR, Gomes HP, da Fonseca MHZ, Hoffman JC, Pederneiras SG, Garcia JHS. Predictors of successful neuraxial block: a prospective study. Eur J Anaesthesiol. 2002;19(6):447-51. doi: 10.1097/00003643-200206000-00008.

5. Drasner K, Larson MD. In: Basics of anesthesia. Stoelting RK, Miller RD, editors. Philadelphia: Churchill Livingstone Elsevier; 2007. pp. 24171.Spinal and epidural anesthesia.

6. Fisher KS, Arnholt AT, Douglas ME, Vandiver SL, Nguyen DH. A randomized trial of the traditional sitting position versus the hamstring stretch position for labor epidural needle placement. Anesth Analg. 2009;109(2):532-4. doi: 10.1213/ane.0b013e3181ac6c79. [PubMed: 19608828].

7. Soltani Mohammadi S, Hassani M, Marashi S M. Comparing the Squatting Position and Traditional Sitting Position for Ease of Spinal Needle Placement: A Randomized Clinical Trial. Anesth Pain Med. 2014;4(2):e13969. doi: 10.5812/aapm.13969.

8. Shabanian G, Saadat M. A position for administration of difficult spinal anesthesia. J Clin Diagn Res. 2014;8(3):190-1. doi: 10.7860/JCDR/2014/5881.4198. [PubMed: 24783134].

9. Grau T, Leipold RW, Horter J, Conradi R, Martin E, Motsch J. The lumbar epidural space in pregnancy: visualization by ultrasonography. $\mathrm{Br} J$ Anaesth. 2001;86(6):798-804. [PubMed: 11573586].

10. Tekeoglu I, Adak B, Bozkurt M, Gurbuzoglu N. Distraction of lumbar vertebrae in gravitational traction. Spine (Phila Pa 1976). 1998;23(9):1061-3. [PubMed: 9589547] discussion 1064.

11. Shankar H, Rajput K, Murugiah K. Correlation between spinous process dimensions and ease of spinal anaesthesia. Indian J Anaesth. 2012;56(3):250-4. doi:10.4103/0019-5049.98769. [PubMed: 22923823].

12. Sukmono RB. In: Buku ajar anestesiologi. Jakarta: Departemen Anestesiologi dan Intensive Care Fakultas Kedokteran Universitas Indonesia/RS Cipto Mangunkusumo Jakarta. Soenarto RF, Chandra S, editors. ; 2012. pp. 451-75.Anestesia regional.

13. Brooks RR, Oudekerk C, Olson RL, Daniel C, Vacchiano C, Maye J. The effect of spinal introducer needle use on postoperative back pain. AANA J. 2002;70(6):449-52. [PubMed:12526150]. 